\title{
A STUDY ON FORMULATION AND ACCEPTABILITY OF ANTI-COLD MOCKTAILS WITH VITAMIN C ENRICHED INGREDIENTS
}

\author{
ARUN A*, DISALVA X, MURALI M \\ School of Catering and Hotel Management, Vels Institute of Science, Technology and Advanced Studies, Chennai, \\ Tamil Nadu, India. Email: arunarticle2016@gmail.com
}

Received: 10 July 2018, Revised and Accepted: 25 July 2018

\section{ABSTRACT}

Objectives: Common cold is a widespread respiratory infection among all age groups. This creates a great nuisance and discomfort making a person feels ill. Common cold can also be treated with home-made remedies. The study gives attention to develop and formulate Mocktail drinks with Vitamin $\mathrm{C}$ enriched ingredients to fight against cold.

Method: Developed Mocktails are tested for the presence of vitamins, and evaluated with sensory evaluation among 50 panelist members, feedback data collected are analyzed with statistical software SPSS (21.0).

Results: The study exhibits that the formulated recipes of Mocktails are identical in aroma analysis with one-way ANOVA test proves, the recipes are significantly different in taste and appearance. The Freidman's test shows that the Mocktail with pineapple juice (Code C) is more preferred by panelist members.

Conclusion: The developed Mocktail recipes are rich in Vitamin C and significantly different in their organoleptic parameters furthermore preferably acceptable.

Keywords: Acceptance, Cold, Ingredients, Mocktails, Vitamin C.

(C) 2018 The Authors. Published by Innovare Academic Sciences Pvt Ltd. This is an open access article under the CC BY license (http://creativecommons. org/licenses/by/4. 0/) DOI: http://dx.doi.org/10.22159/ajpcr.2018.v11i12.27535

\section{INTRODUCTION}

Nowadays, youngsters are more aware that healthy living can be achieved only by a well-organized and healthy diet practice constituting an elaborate range of healthy ingredients in their food habit. Beside routine juices and packaged drinks, the Mocktail, a blended nonalcoholic drink of fresh fruit juices with squashes, flavored water, herbs, or spices [1] are more preferred for their healthy properties.

Mocktails recipes are more oriented toward the mixture of herbs and spices with fresh juice extracts from the fruits such as mangoes, pineapple, orange, and pomegranate rich in antioxidants and vitamins. Consumption of these drinks improves their immunity [2]. These drinks are less expensive, more colorful and unique in taste which can be also consumed by children and pregnant ladies [3].

The bartenders at present scenario act as an expert mixologist formulating the recipes with more nutritive and medicinal ingredients as their guest are more knowledgeable and responsive to what they drink [4]. The space for these non-alcoholic drinks are more projected at the food and beverage outlets as the customer's preference for herbal and health-based Mocktails are gradually increasing [5]. Alcoholics consume these drinks to reduce their strong alcohol consumptions and make their following days fresh for work [6]. Formulating the recipes for Mocktail depends on the expertise, skill, and innovative thinking of the food and beverage personnel.

The study involves the formulation and standardizing of three anti-cold Mocktail recipes with fruitjuices rich in Vitamin C such as papaya, orange, and pineapple, and good source of Vitamin C [7]. Vitamin C acts as an alternative medicine for common cold, a gram per day decreases the symptom around $8 \%$ in adults and $18 \%$ in children [8]. The other commonly available anticold ingredients such as Indian borage (Plectranthus amboinicus) [9], honey [10], and ginger [11] are also used in the preparation of Mocktails. Mint leaves [12] and Strawberry [7] another rich source of Vitamin C and help to fight cold [13] is used for garnishing the drinks.

\section{METHODS}

The study was carried out at School of Catering and Hotel Management, Vels University, Chennai. Three types of Mocktails are prepared using the fruit juices of papaya, pineapple, and orange.

\section{Collection of ingredients}

Ingredients used in the preparation of Mocktails papaya, pineapple, orange, strawberry, and honey are bought from the organic stores. The herbs Indian borage and mint leaves are identified and collected freshly from the botanical garden maintained at Vels University, Pallavaram campus.

\section{Preparation of fresh fruit juices}

Fruits bought from the stores are washed and cleaned under running water and then are individually peeled; seeds are removed, sliced, and kept aside. Then, the fruits are separately blended in a blender strained and kept aside.

\section{Preparation of borage extract}

Indian borage leaves are freshly collected and separated from stem, washed under running water. The leaves are tossed in a hot pan then removed and cooled. The leaves are finally blended without adding water to it and then strained.

\section{Preparation of ginger extract}

Fresh ginger is washed under running water, checked for any mud particles and peeled. Then, it is chopped finely, blended, strained, and the extract is kept aside for further use.

\section{Preparation and coding of the Mocktails}

Once the juices and borage extract have been prepared that the Mocktails are then blend together. The three Mocktails differ according the fruit juices added as the other base ingredients, and the garnishing remains the same for all three types. The juice, extracts, and honey are 
added to the shaker and shacked well and then garnished with a sliced strawberry and chopped mint leaves. Mocktail prepared with orange juice is coded as CODE A, with papaya is coded as CODE B, and with pineapple juiced is coded as CODE C. The ingredient for three Mocktail recipes is exhibited in Table 1.

Bottling and storage of fruit juices and extractions

Once the juices and extracts are prepared, they are stored separately. Refrigeration of the juices and extract should be avoided. It is advisable to blend the Mocktail once the juice and borage have been prepared for an exceptional taste and effective result.

\section{Qualitative analysis of vitamins}

\section{Test for Vitamin A}

Dissolve quantity equivalent to $10-15$ units in $1 \mathrm{ml}$ of chloroform and add $5 \mathrm{ml}$ of antimony trichloride solution, a transient blue color is produced immediately.

\section{Test for Vitamin $C$}

Dilute $1 \mathrm{ml}$ of $2 \% \mathrm{w} / \mathrm{v}$ solution with $5 \mathrm{ml}$ of water and add 1 drop of freshly prepared $5 \% \mathrm{w} / \mathrm{v}$ solution of sodium nitroprusside and $2 \mathrm{ml}$ of dilute sodium hydroxide solution. Add $0.6 \mathrm{ml}$ of HCL dropwise and stir, the yellow color turns blue.

\section{Test for Vitamin D}

Dissolve a quantity equivalent to about 1000 units of Vitamin D activity in chloroform and add $10 \mathrm{ml}$ of antimony trichloride solution, a pinkishred color appears at once.

\section{Test for Vitamin E}

$500 \mathrm{mg}$ of the sample powder was macerated with $10 \mathrm{ml}$ of ethanol for $5 \mathrm{~min}$ and then filtered. Few drops of $0.1 \%$ ferric chloride in ethanol and $1 \mathrm{ml}$ of $0.25 \%$ of 2 '-2'dipyridyl to $1 \mathrm{ml}$ of the filtrate. Bright-red color was formed on a white background. The background gradually assumes a pink [14].

\section{Sensory evaluation test}

The sensory evaluation is always important to be conduction when developing a new recipe to check the acceptance of the targeted population [15]. The sensory evaluation test was conducted among the 50 panelist members, randomly selected students from the Department of Catering and Hotel Management, Biochemistry, and Bioinformatics for the study to be more reliable. The panelist was divided into five groups with 10 members, in five sessions all three Mocktails were served together among the panelist giving a perfect interval of time for the best result. The protocol was approved by the Institutional Human Ethical Committee and informed; consent was obtained from the participants.

A hedonic scorecard rating (Table 2) and a simple paired questionnaire (Table 3) is prepared and distributed among the panelist to register their feedback about the three Mocktails. From Table 2, the panelists were asked to evaluate the organoleptic qualities of the Mocktails such as color, taste, aroma, appearance, and their overall acceptance. The scale was ranging from 1-(dislike extremely) to 9-(like extremely). Table 3 was used to bring out preference of the Mocktail among the panelist. All feedbacks were received, and data are segregated for further statistical analysis.

\section{Nutritive value calculation}

The nutritive values of the Mocktails are calculated as per the ingredients nutritive values. The book is referred to as the reference of nutritive values of the ingredients.

\section{Statistical analysis}

The data received from the panelists were fed and analyzed with the SPSS (21.0) statistical tool. Data were checked for reliability and descriptively analyzed. The organoleptic qualities of three coded Mock-tails were correlated (Pearson correlation test) and analyzed with One-Way ANOVA test to check whether there exists any relation in sensory parameters. The Mock-tails were also ranked using the Friedman Test [16].

\section{RESULTS AND DISCUSSION}

The sensory evaluation data for the organoleptic parameters of the three Mocktails were correlated (Pearson correlation test) among each other to check whether there exists any interrelation among the organoleptic parameters.

Table 1: Ingredients for Mocktails

\begin{tabular}{lll}
\hline CODE A & CODE B & CODE C \\
\hline 3 Part orange juice & 3 Part of papaya juice & 3 Part of pineapple juice \\
1 Part Indian Borage Extract & 1 Part Indian Borage Extract & 1 Part Indian Borage Extract \\
1 Part ginger extract & 1 Part ginger extract & 1 Part ginger extract \\
Organic honey-20 ml & Organic honey-20 ml & Organic honey-20 ml \\
Strawberry and mint leaves (to garnish) & Strawberry and mint leaves (to garnish) & Strawberry and mint leaves (to garnish) \\
\hline
\end{tabular}

Table 2: Sensory evaluation sheet for evaluating Mocktail recipes

Sample-hedonic score card rating

Date: Panelist Name:

Mock tail code: Panelist No

Please taste the given coded Mocktail and mark $(\checkmark)$ how much you like or dislike it on the point in the scale which bests describes your opinion

\begin{tabular}{|c|c|c|c|c|c|c|}
\hline S. no. & Hedonic score & Color & Taste & Aroma & Appearance & Acceptance \\
\hline 1 & Dislike extremely & & & & & \\
\hline 2 & Dislike very much & & & & & \\
\hline 3 & Dislike moderately & & & & & \\
\hline 4 & Dislike slightly & & & & & \\
\hline 5 & Neither like nor dislike & & & & & \\
\hline 6 & Like slightly & & & & & \\
\hline 7 & Like moderately & & & & & \\
\hline 8 & Like very much & & & & & \\
\hline 9 & Like extremely & & & & & \\
\hline
\end{tabular}


Table 3: Paired comparison questionnaire

\begin{tabular}{lll}
\hline \multicolumn{3}{l}{ Paired comparison questionnaire } \\
\hline \multicolumn{2}{l}{ Please taste and mark $(\checkmark)$ at appropriate boxes } \\
\hline S. No & Particulars & Feed back \\
\hline 1 & All coded Mocktails are alike & \\
2 & Code A is better than B and C \\
3 & Code B is better than A and C \\
4 & Code C is better than B and C \\
\hline
\end{tabular}

Table 4: Correlation of aroma between the Mocktails

\begin{tabular}{llll}
\hline S. No & Codes & $\begin{array}{l}\text { Correlation } \\
\text { value }(\mathbf{r})\end{array}$ & $\begin{array}{l}\text { Significance } \\
\text { level }\end{array}$ \\
\hline 1 & CODE A and CODE B & 0.486 & 0.05 \\
2 & CODE B and CODE C & 0.325 & $0.02(<0.05)$ \\
3 & CODE C and CODE A & 0.669 & 0.05 \\
\hline
\end{tabular}

Table 5a: Ranking preferences of Mocktails

\begin{tabular}{ll}
\hline Code & Mean rank \\
\hline CODE A & 2.39 \\
CODE B & 2.05 \\
CODE C & 1.56 \\
\hline
\end{tabular}

Table 5b: Test statistics ${ }^{\mathrm{a}}$

\begin{tabular}{ll}
\hline $\mathrm{n}$ & 50 \\
Chi-square & 18.230 \\
Df & 2 \\
Asymp. Sig. & 0.000 \\
\hline
\end{tabular}

${ }^{\mathrm{a} F r i e d m a n}$ test

Table 6: Vitamin analysis of samples

\begin{tabular}{lllll}
\hline S. No & Constituent & \multicolumn{3}{c}{ Concentration level in Mocktails } \\
\cline { 3 - 5 } & & CODE A & CODE B & CODE C \\
\hline 1 & Vitamin A & + & ++ & + \\
2 & Vitamin C & ++ & ++ & ++ \\
3 & Vitamin D & + & + & + \\
4 & Vitamin K & + & ++ & + \\
\hline +: Indicates presence, ++: Indicates high concentration, -: Indicates absence
\end{tabular}

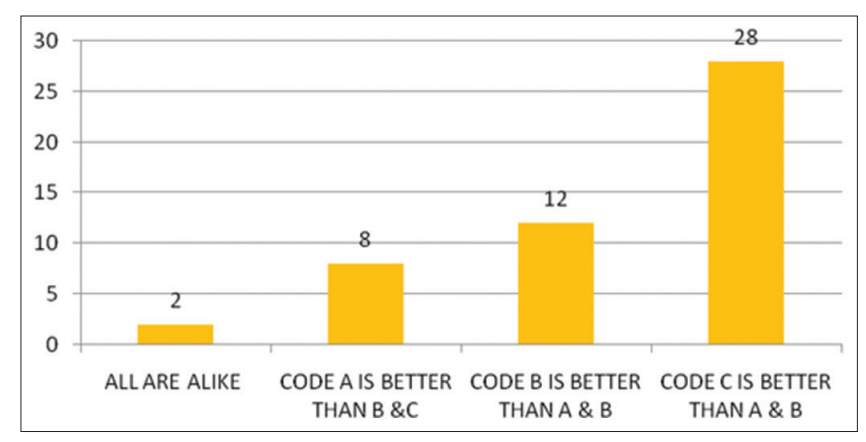

Fig. 1: Panelist's preference feedback on the Mock-tails

Color

With regard to color, CODE A and CODE C correlates each other $(r=0.279)$ and significant at 0.5 level showing that the color of CODE A and CODE $\mathrm{C}$ resembles each other.
Aroma

The aroma of the three Mocktails is, moreover, identical as they correlate with each other (Table 4). This may be due to the strong aroma of Indian borage being added as an ingredient. The strong aroma of Indian Borage has suppressed the aroma of fruits.

\section{Taste}

The analysis with one-way ANOVA test for the parameter (taste) shows ( $F$ value -5.53872 ) significant at $p=0.004796$ that there is no significant relation in taste among the three coded Mocktails.

\section{Appearance}

There exists no positive correlation between the Mocktails. The ANOVA test also shows that the appearance is significantly different from each other with f-value 7.4701 and significant at $\mathrm{p}<0.05$ level.

The feedback from the panelist also summarized that the consistency level and the taste of all three Mocktail recipes were significantly differed from one another.

\section{Friedman test}

Friedman test exhibits the ranking preferences of the three Mocktail drinks. From the below Tables 5a and b, the Chi-square value (18.230) is high showing that there exist distinct differences among the three Mocktails. Among the three Mocktail recipes, CODE C is more preferred and ranked first with mean ranking value (1.56).

\section{Panelist's preference feedback}

Panelist has been issued with a paired comparison questionnaire to evaluate the three Mocktail drinks. Fig. 1 exhibits the feedback of the panelist member which shows that among the 50 panelists only 2 members felt that the all three Mocktails are alike besides 28 panelist members have marked that the Mocktail drink CODE C is better than other two drinks.

\section{Analysis for vitamins}

The laboratorial test proves the presence of vitamins in formulated Mocktails, Table 6 shows their levels of concentration according to the table there exist a high concentration of Vitamin C, besides there other vitamins such as Vitamin A, Vitamin D, and Vitamin K are also present in the formulated drink.

\section{CONCLUSION}

Mocktails are internationally known drink being preferred by all customers, the study concludes that the three Mocktail drinks are significantly different, nutritive and best alternative medicine for cold. The study suggests that the innovative thinking in formulating these Mocktail recipes with traditional and healthy ingredients makes the drink more value-added and preferred by the customers and commercially successful.

\section{ACKNOWLEDGMENT}

Authors thank the department head of hotel and catering management and the panelist member from hotel management and other department to make the research work successful. Vels Institute of Science, Technology and Advanced Studies, Chennai, has sponsored by providing grant to publish this article.

\section{AUTHORS' CONTRIBUTIONS}

A. Arun and X. Disalva considered and designed the study. Chef. M. Murali performed the experiment data collection. The manuscript was done and revised by A. Arun.

\section{CONFLICTS OF INTEREST}

There exist no conflicts of interest among any authors. Authors effectively participated in the practical study and composition of manuscript. 


\section{REFERENCES}

1. Mock-Tails-Definition. English Oxford Living Dictionaries. Available from: https://www.en.oxforddictionaries.com/definition/Mock-tail. [Last cited on 2017 Oct 8 ].

2. Desjardins D. Reasons Your Menu Should Include Mock-tails. Available from: https://www.rewardsnetwork.com/blog/3-reasons-menu-includeMock-tails. [Last cited on 2017 Oct 12].

3. Mock-Tail Benefits. Think B4 U Drink. Available from: http://www. thinkb4udrink.org/health/Mock-tail-benefits. [Last cited on 2017 Oct 18].

4. Dunn EG. Mock-Tails Come of Age. The Wall Street Journal. Available from: https://www.wsj.com/articles/Mock-tails-come-ofage-1391195295. [Last cited on 2017 Oct 9]

5. Fry N. The Evolving Non-Alcoholic Beverage Landscape. A First Beverage Group Perspective. Available from: http://www.firstbev.com/ wordpress/wp-content/uploads/2015/03/FBG_Non-Alc-White-Paper_ March-2015.pdf. [Last cited on 2017 Oct 9].

6. Danovich T. The Mock-tail Revolution is growing as More Restaurants Adopt Booze-Free Libations. Available from: https://www.eater.com/ drinks/2015/7/13/8947439/the-Mock-tail-revolution-is-growing-asmore-restaurants-adopt-booze. [Last cited on 2017 Oct 9].

7. Moalem S. Nutrition9 Foods with More Vitamin C than Oranges. Available from: https://www.rodalewellness.com/food/9-foods-withmore-vitamin-c-than-oranges. [Last cited on 2017 Oct 9].

8. Nahas R, Balla A. Complementary and alternative medicine for prevention and treatment of the common cold. Can Fam Physician 2011;57:31-6

9. Arumugam G, Swamy MK, Sinniah UR. Plectranthus amboinicus (Lour.) spreng: Botanical, phytochemical, pharmacological and nutritional significance. Molecules 2016;21:369.

10. Eteraf-Oskouei T, Najafi M. Traditional and modern uses of natural honey in human diseases: A review. Iran J Basic Med Sci 2013;16:731-42.

11. Bode AM, Dong Z. The amazing and mighty ginger. In: Benzie IF, Wachtel-Galor S, editors. Herbal Medicine: Biomolecular and Clinical Aspects. $2^{\text {nd }}$ ed. Boca Raton (FL): CRC Press/Taylor and Francis; 2011.

12. Singh R, Shushn MA, Belkheir A. Antibacterial and antioxidant activities of Mentha piperita L. Arab J Chem 2015;81:322-8.

13. Ware RD. Strawberries: Health Benefits, Nutritional Breakdown. Reviewed by University of Illinois-Chicago, School of Medicine. Available from: https://www.medicalnewstoday.com/articles/271285. php. [Last cited on 2017 Oct 9].

14. Pearson D. Chemical Analysis of Foods. $7^{\text {th }}$ ed. London: Churchchill, Livingstone; 1976. p. 218-336.

15. Singham $P$, Birwal $P$, Yadav BK. Importance of objective and subjective measurement of food quality and their inter-relationship. J Food Process Technol 2015;6:488.

16. Rayner JW, Best DJ. A comparison of some rank tests used in tastetesting. J R Soc N Z 1990;20:269-72. 